\title{
Variability of the Circle of Willis in North American Caucasian and Middle East Arabic Cohorts
}

\author{
Maryna Kornieieva1, Azmy Hadidy², Ashirbad Panta ${ }^{3}$, Melody Abadpour ${ }^{3}$ \\ ${ }^{1}$ Department of Anatomy, Embryology and Histology, School of Medicine, American University of Caribbean, Philipsburg, \\ Sint Maarten \\ ${ }^{2}$ Department of Diagnostic Radiology and Nuclear Medicine, Hospital of University of Jordan, University of Jordan, Amman, \\ Jordan \\ ${ }^{3}$ School of Medicine, American University of Caribbean, Philipsburg, Sint Maarten \\ Email: mkornieieva@aucmed.edu
}

How to cite this paper: Kornieieva, M., Hadidy, A., Panta, A. and Abadpour, M. (2021) Variability of the Circle of Willis in North American Caucasian and Middle East Arabic Cohorts. Open Journal of Modern Neurosurgery, 11, 7-19.

https://doi.org/10.4236/ojmn.2021.111002

Received: October 1, 2020

Accepted: December 6, 2020

Published: December 9, 2020

Copyright (c) 2021 by author(s) and Scientific Research Publishing Inc. This work is licensed under the Creative Commons Attribution International License (CC BY 4.0)

http://creativecommons.org/licenses/by/4.0/

\begin{abstract}
The cerebral arterial circle (circle of Willis) plays an important role in the redistribution of the blood flow between the anterior and posterior territories and maintains the plasticity of the cerebral blood circulation. The anatomical variability of the vascular circle often alters the cerebral hemodynamics and determines the outcomes of acute and chronic cerebrovascular disease. The heritability and prevalence of certain variants of the circle of Willis in different ethnic and racial groups are frequently disputed by authors. Our cross-sectional retrospective study aims to compare the patterns of the cerebral arterial circle in 64 Caucasian cadavers with 64 Arabic living individuals, by methods of anatomic dissection and magnetic resonance angiography, respectively. The typical structure of the circle of Willis was revealed in $8.3 \%$ of the Caucasian study group, and in $22.2 \%$ of the Arabic one. The anterior part of the circle of Willis was incomplete in 6 out of 64 of the Caucasian specimens, where the anterior communicating artery was hypoplastic $(6.3 \%)$ or absent (3.1\%). The posterior part of the circle of Willis had hypoplastic or absent posterior communicating artery on one side in 20 , and on both sides in 12 out of 64 Caucasian specimens. In the Arabic cohort, the posterior part of the circle of Willis was incomplete in 17 out of 64 specimens, with absence of the posterior communicating artery unilaterally (in 11 cases) or bilaterally (in 6 cases). The present study reveals that the configuration of the cerebral arterial circle and distribution of the blood flow between the anterior and posterior territories have certain differences in the Caucasian study group versus the Arabic one.
\end{abstract}




\section{Keywords}

Arterial Cerebral Circle, Anterior Circulation, Posterior Circulation, Fetal Cerebral Circulation

\section{Introduction}

Cerebrovascular disease is a leading cause of disability and one of the five top causes of death in the United States and worldwide [1]. The risk of cerebrovascular disease is primarily determined by the efficiency of the intracranial collateral cerebral circulation. At the base of the brain, the anterior and posterior communicating arteries link the internal carotid and basilar arteries into a cerebral arterial circle, also known as the circle of Willis. This structure provides an immediate redistribution of the blood flow in case of acute obstruction of the internal carotid or basilar arteries. In case of atherosclerotic occlusion with the aforementioned vessels, these anastomoses facilitated the means of a by-pass circulation to compensate for pathological deficits [2]. Thus, the presence of well-developed anastomotic vessels in the cerebral arterial circle of Willis is the main life-saving factor in the patients with both acute and chronic cerebrovascular pathologies.

The review of literature shows that the complete arterial ring develops only in $14.5 \%$ - 37\% of individuals, and vascular components of CW exhibit a wide range of anatomic variations [3] [4] [5] [6]. In their extensive study on 507 samples, Chen et al. [4] classified variations of the anterior and posterior parts of the $\mathrm{CW}$ by twenty types based on unilateral and bilateral hypoplasia or aplasia of each contributing vessel. Comparison of the data obtained from the various populations shows unequal distribution of the types of the circle of Willis, and wide range of development of its components from aplastic to hypertrophic [7] [8] [9]. For instance, the unilateral hypoplastic posterior communicating artery was observed in $14.5 \%$ of Caucasian and in $42.8 \%$ of Asian cohorts [6] [8]. The hypoplastic pre-anastomotic segment of the anterior cerebral artery (A1) was found in $11.44 \%$ of cases in the research hold in Kenya, and only in $2 \%$ of brain specimens taken in Morocco [3] [7]. Does this difference reflect a genetic divergence of studied cohorts and may it be extrapolated to the whole population?

The heritability of variations of the circle of Willis is frequently discussed in literature. Findings of Kammen et al. [10], who assessed the variability of the circle of Willis in families with familial aneurisms, show that the formation of the posterior communicating artery has a heritable predisposition. In their genetic research on gerbils, Li Z. et al. [11] have identified 4 specific genes (CST3, GNAS, GPx4 and PFN2) associated with variations in the circle of Willis, providing a strong foundation for further research in this area. Understanding the main features of the anatomic variability and associated cerebrovascular pathology in different populations would help to adapt the prognosis, evaluation, and treatment approaches significantly. 
In this research, we compare the anatomical variability of the circle of Willis in two racially different cohorts (American Caucasians and Arabs).

\section{Material and Methods}

Our cross-sectional retrospective study was carried out on 128 specimens taken from two different population representative cohorts. The first cohort included sixty-four randomly selected patients of Arab descent (30 males and 32 females), aged between 35 and 79 years old, without known cerebrovascular pathology, who underwent routine magnetic resonance (MR) examination of the head and neck in accordance with international ethical standards. The second study group included sixty-four Caucasian cadavers, all former residents of North America (36 male and 28 female), aged between 54 and 86 years; who underwent routine educational craniotomy. All body donors were fully legally competent and had a will in which they agreed to the use of their body or body parts for research, study, or teaching purposes.

The MRI scans were performed with a use of a whole-body 3 Tesla MR system (Magnetom Verio; Siemens Medical Solution, Erlangen, Germany). The protocol was identical for all participants and included axial and sagittal T1 and T2-weighted ultra-fast gradient echo sequences (280/2.6 [repetition time $\mathrm{ms} / \mathrm{echo}$ time $\mathrm{ms}$; flip angle $15 \mathrm{u}, 230 \mathrm{~mm}$ field of view with a 0.10 distant factor).

To obtain the brain specimens the circular craniotomy was performed using an electric bone-saw. The dura mater was cut longitudinally alongside the superior sagittal sinus and detached from the frontal crest anteriorly and the posterior clinoid processes posteriorly. The brain was carefully extracted from the cranial cavity, following the transection of the cranial nerves and blood vessels, and rinsed with running water.

On both MR angiograms and brain specimens, the main components of the cerebral arterial ring, such as the anterior communicating artery (Acom), anterior cerebral artery (precommunicating segment A1, postcommunicating segment A2), middle cerebral artery (MCA), posterior communicating artery (Pcom), posterior cerebral artery (precommunicating segment P1, postcommunicating segment P2), basilar and internal carotid arteries (BA and ICA, respectively), were identified. On the brains, the diameters of the listed vessels were measured using an IP54 digital caliper three times on each segment and the calculated average was recorded as the value. The MRI images underwent 3D volume rendering, then analyzed and measured in a RadiAnt DICOM viewer (version 3.4.2). Since the vessels with the diameters less than $0.8 \mathrm{~mm}$ are not visualized on MR angiograms [12], the cadaveric arteries with the diameter less than $0.8 \mathrm{~mm}$ were considered as ineffective, and the circle of Willis with one or more of these types of vessels was classified as incomplete. The arteries with the diameter $0.8-1 \mathrm{~mm}$ were considered hypoplastic.

All specimens were subdivided into 3 groups according to the development of 
the main components of the cerebral arterial circle: 1) complete; 2 ) incomplete anterior part; 3) incomplete posterior part with or without fetal circulation.

In the specimens with the developed Pcom, the contribution of the anterior and posterior cerebral circulation in the feeding of the posterior cerebral arteries was evaluated using the ratio of diameters P1/Pcom. The coefficient of dominance (CD) was introduced to solidify the difference between the "partial fetal" and "complete fetal" circulation commonly used by authors [13] [14]. The value $>1.2$ was considered as the dominance of the $\mathrm{BA}$ in feeding of the posterior cerebral territories; the value $<0.8$ indicated the dominant contribution of the ICA; while the value from 0.81 to 1.19 assumed the equal participation of both major blood sources. Respectively, the specimens with well-developed Pcom were subdivided into 1) BA dominant (normal), 2) ICA dominant (complete fetal circulation); 3) ICA and BA co-perfusion (partial fetal circulation).

The methods of descriptive statistics were used to process the obtained morphologic data. The means and standard deviations of resultant data were calculated and analyzed in each studied group individually using SPSS for Windows v.24 software. The paired t-test was used to detect differences in the obtained data in the compared groups $(\mathrm{p} \leq 0.05)$.

\section{Results}

The typical complete circle of Willis was revealed in $8.3 \%$ of the Caucasian, and in $22.2 \%$ of the Arabic specimens (Figure 1). The anterior part of the circle of Willis was incomplete in 6 out of 64 of the Caucasian study group, where the anterior communicating artery was hypoplastic $(6.3 \%)$ or absent $(3.1 \%)$. In all cases, the anterior cerebral arteries branched off and were fed from the ipsilateral internal carotid artery (Table 1). In the same number of the Arabic specimens, the anterior communicating artery was deficient in 14 cases. In 6 of them, the A1 segment was absent on one side and both anterior cerebral arteries were fed by the unilateral internal carotid (Figure 2).

The posterior part of the circle of Willis had hypoplastic or absent posterior communicating artery on one side in 20 , and on both sides in 12 out of 64 Caucasian specimens. The unilateral dominance of the diameter of the posterior communicating artery over the diameter of the P1 segment of the posterior cerebral artery was recorded in 24 cases (Figure 3). In the other 6 cases, the posterior communicating arteries fed the posterior cerebral arteries on both sides, while the P1 segments connected with the basilar artery were hypoplastic or absent (Figure 4). In the Arabic samples, the posterior part of the circle of Willis was incomplete in 17 out of 64 specimens, where the posterior communicating artery was absent unilaterally (in 11 cases) or bilaterally (in 6 cases). The features of the fetal circulation were recorded in 16 out of 64 specimens, in $18.7 \%$ unilaterally (Figure 5), and in $6.3 \%$ bilaterally (Figure 6).

The morphometric analysis of the diameters of the vessels of the posterior part of the circle of Willis did not reveal any significant differences (Table 2). 
The arteries appeared to be wider in the Caucasian cohort, however we attribute this difference to the measurement methods for the cadaveric vessels and MRA.

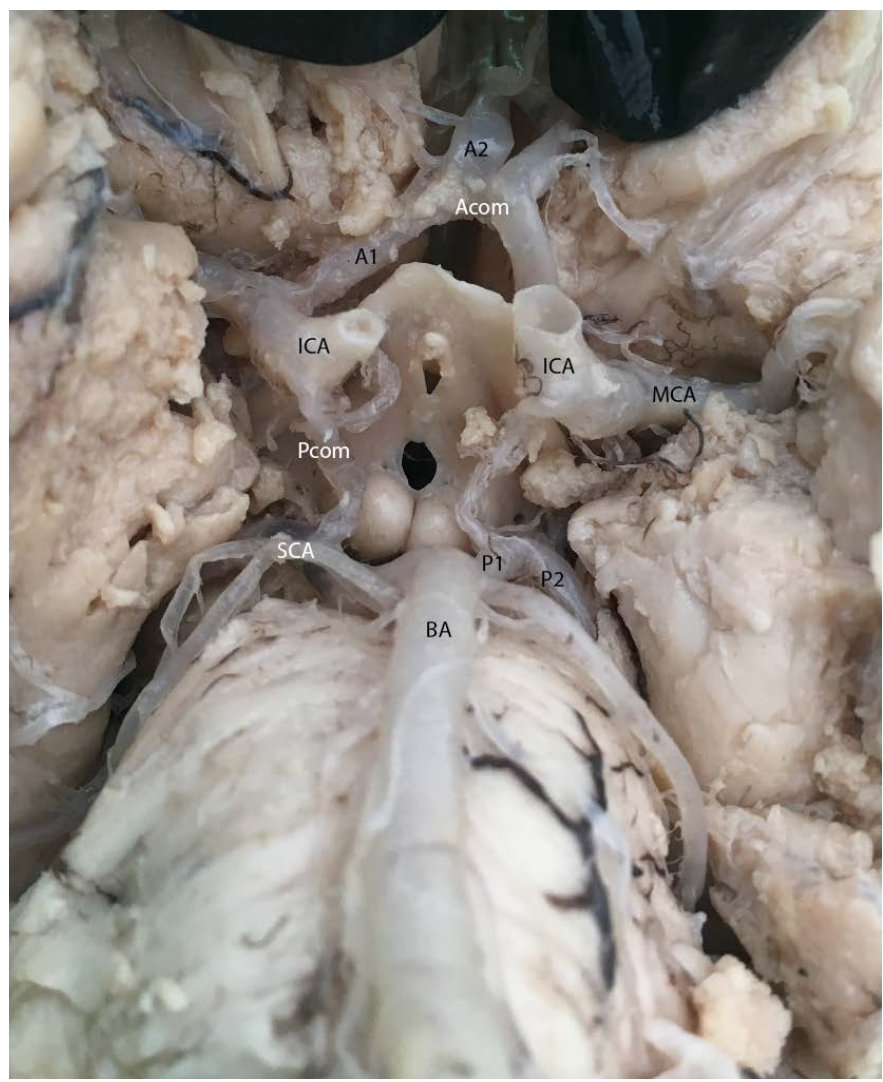

Figure 1. Cadaver dissection view showing the typical configuration of the cerebral arterial ring with well-presented anterior cerebral arteries (A1, A2), anterior communicating artery (Acom), internal carotid artery (ICA), posterior communicating arteries (Pcom), posterior cerebral artery (P1, P2); other abbreviation: MCA: medial cerebral artery, BA: basilar artery; SCA: superior cerebellar arteries.

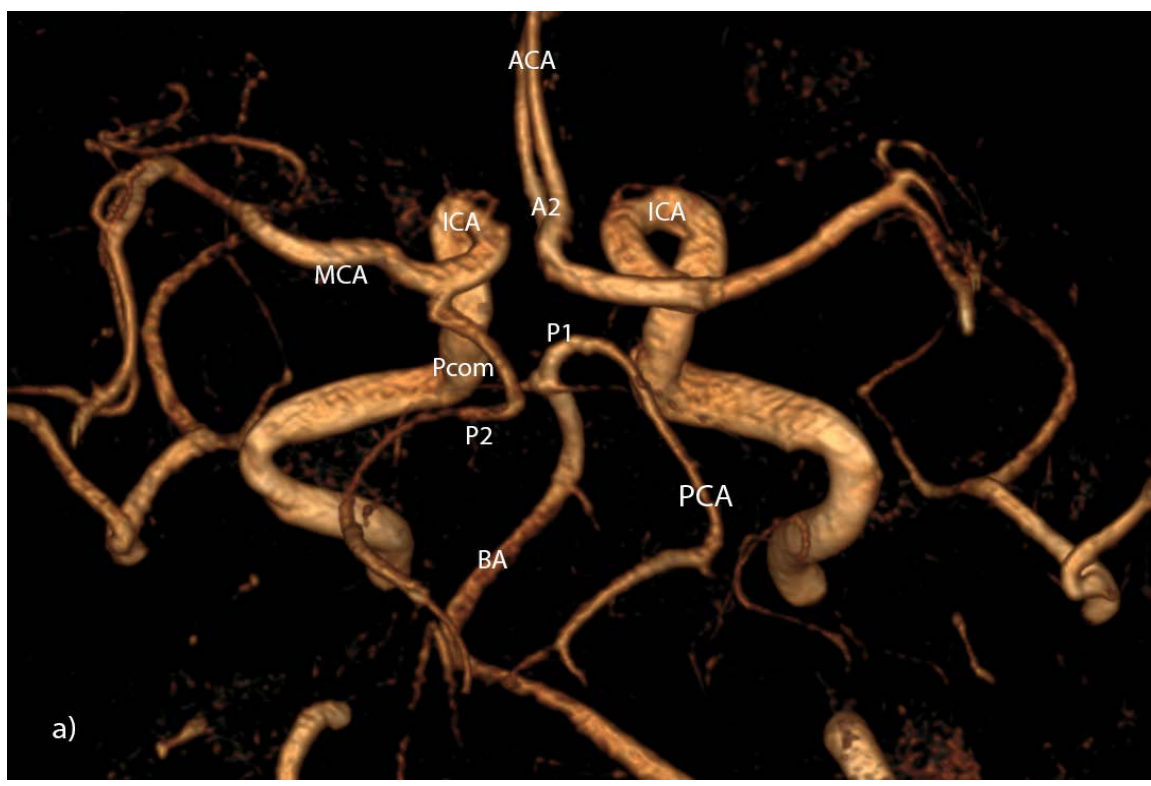




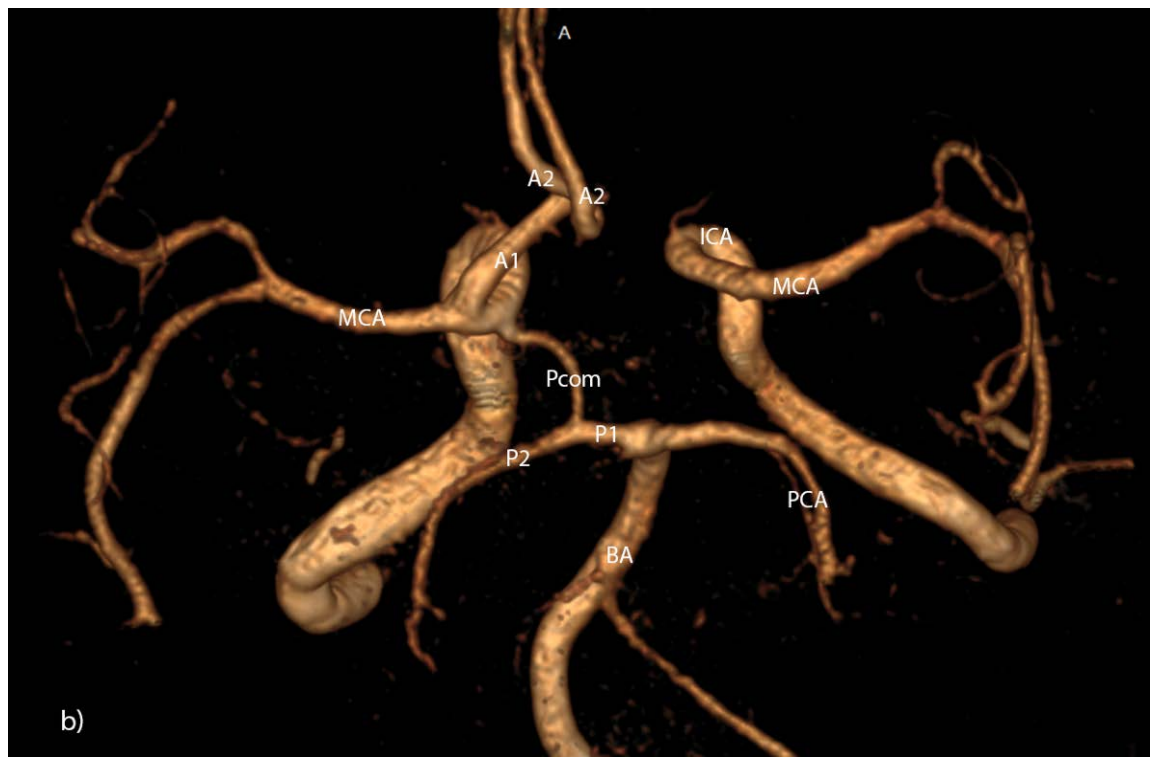

Figure 2. Cerebral MRA, 3D volume rendering (postero-superior view) showing variability of the anterior part of the circle of Willis in Arabic cohort. The anterior communicating segment (A1) is underdeveloped on the right (a) and on the left (b) side, with branching from both postcommunicating segments (A2) from the contralateral internal carotid artery (ICA). Other abbreviations: Pcom: posterior communicating artery, $\mathrm{P} 1$ : precommunicating segment of PCA, P2: postcommunicating segment of PCA, MCA: medial cerebral artery.

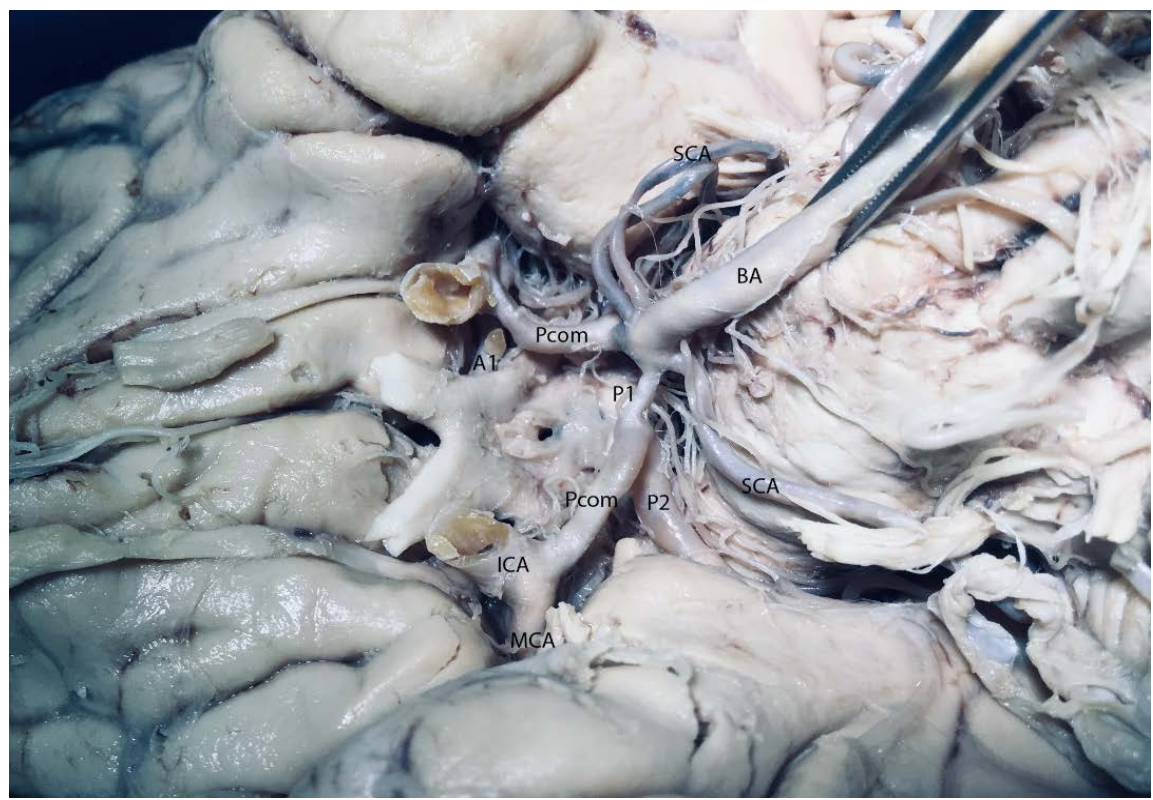

Figure 3. Cadaver dissection view showing the arteries on the ventral surface of the brain; Caucasian specimen. The posterior communicating artery (Pcom) significantly contributes to the posterior cerebral artery (PCA) on both sides of the brain; the small diameter of the precommunicating (P1) segment of the PCA indicates the prevalence of the anterior cerebral circulation in perfusion of the posterior territories of the brain. Other abbreviations: BA: basilar artery; P2: postcommunicating segment of PCA; A1: precommunicating segment of anterior cerebral artery; ICA: internal carotid artery; SCA: superior cerebellar artery (double on the left side). 


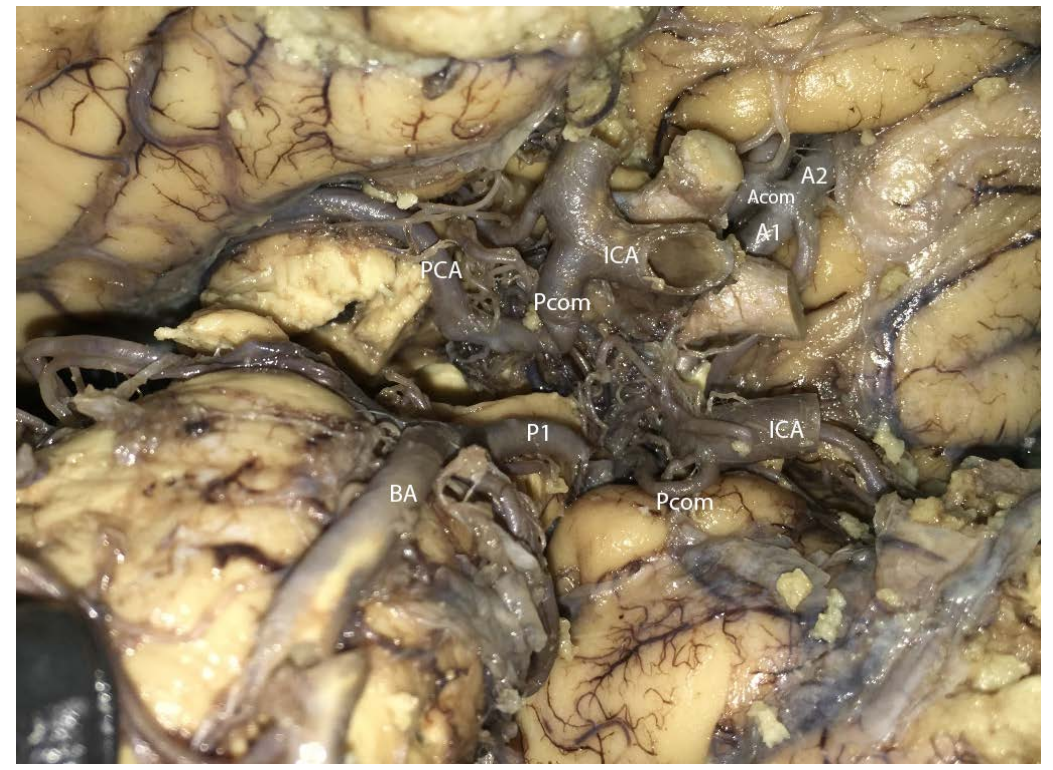

Figure 4. Cadaver dissection view showing the complete dominance of the internal carotid artery (ICA) over the right posterior territory of the brain (complete fetal circulation, Caucasian specimen). The precommunicating segment (P1) of the right posterior cerebral artery is not developed; the basilar artery (BA) supplies the posterior cerebral artery (PCA) on the left side of the brain. Abbreviations: Pcom: posterior communicating artery; P2: postcommunicating segment of the right PCA; A1: precommunicating segment of the anterior cerebral artery; A2: postcommunicating segment of the anterior cerebral artery; Acom: anterior communicating artery.

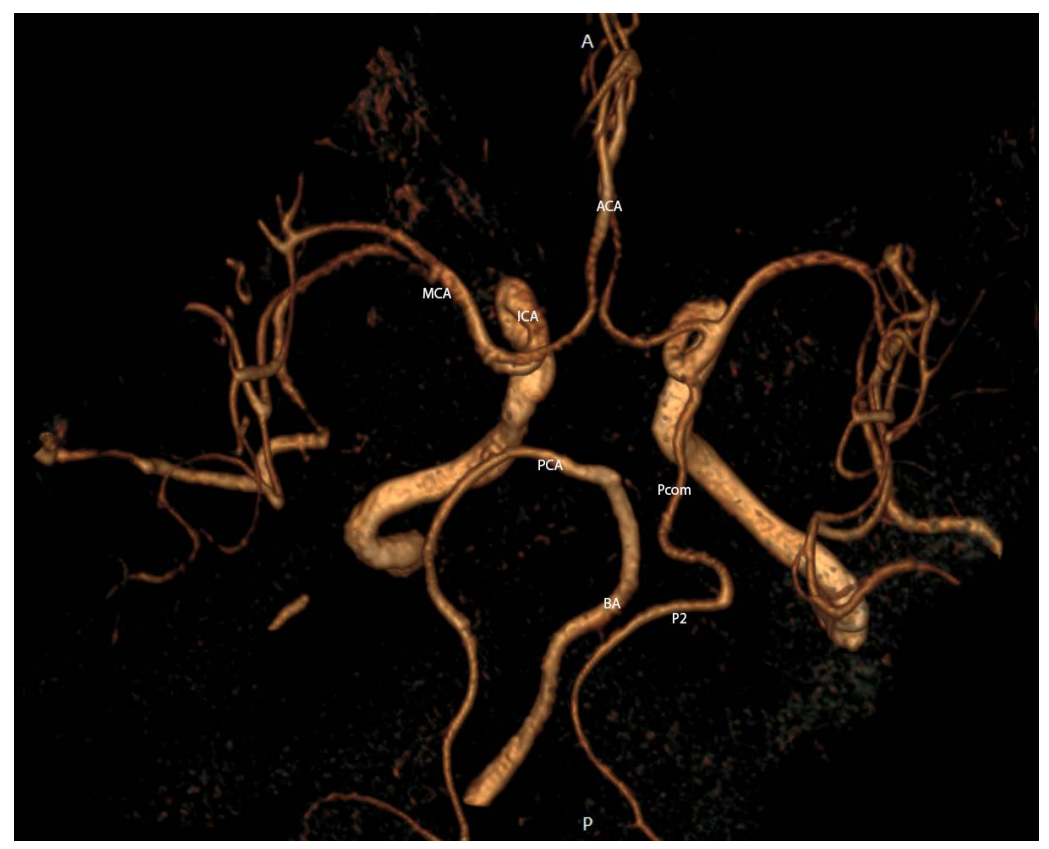

Figure 5. Cerebral MRA, 3D volume rendering (postero-superior view) demonstrating the complete perfusion of the left hemisphere via the internal carotid artery (ICA), known as complete fetal circulation. The left posterior communicating artery (Pcom) continues with the postcommunicating (P2) segment of the posterior cerebral artery (PCA). The basilar artery (BA) is feeding the right PCA. Other abbreviations: ACA: anterior cerebral artery; ICA: internal carotid artery; MCA:medial cerebral artery. 


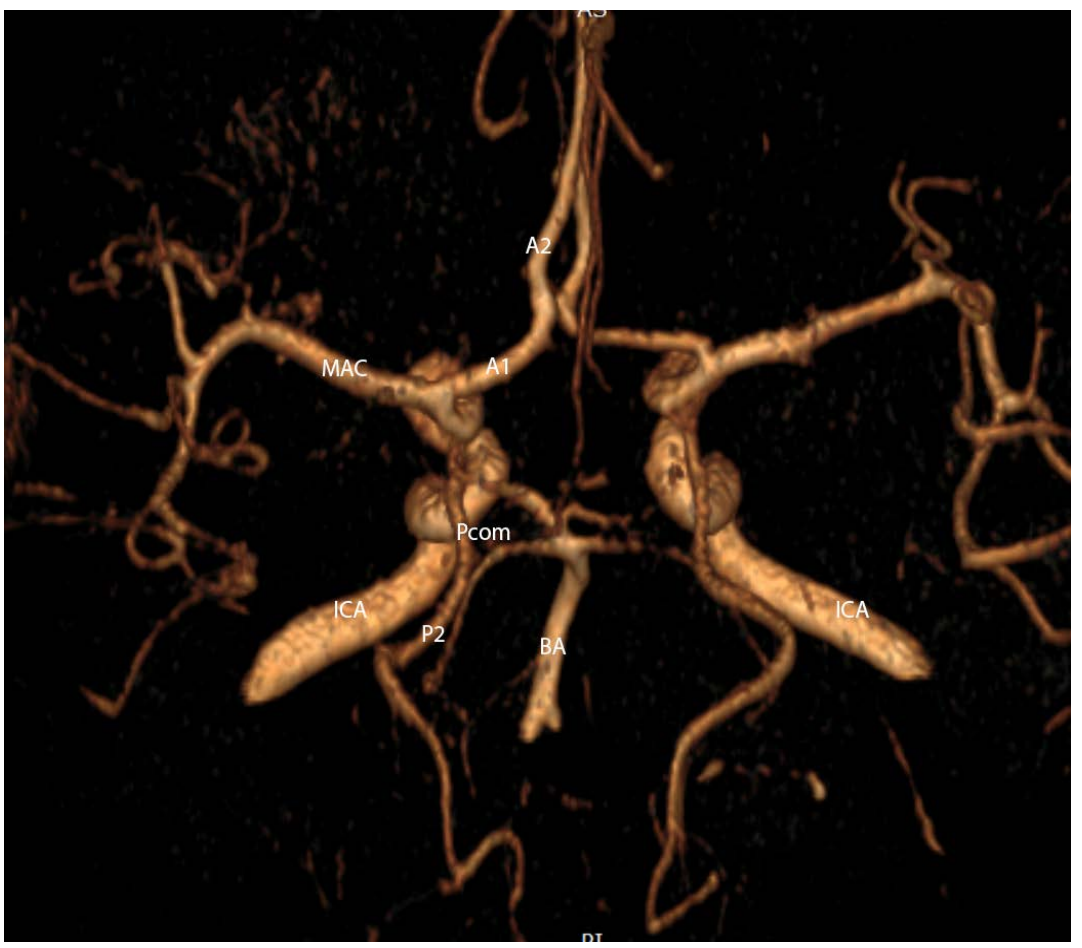

Figure 6. Cerebral MRA, 3D volume rendering (superior view) demonstrating the bilateral dominance of the internal carotid artery (ICA) over the posterior territories (complete fetal circulation). Other abbreviations: Pcom: posterior communicating artery, P1: precommunicating segment of PCA, P2: postcommunicating segment of PCA, A1: precommunicating segment of anterior cerebral artery, A2: postcommunicating segment of the anterior cerebral artery, MCA: medial cerebral artery.

Table 1. Frequencies of variations of the circle of Willis in the Caucasian (NA) and Arabic (ME) cohorts.

\begin{tabular}{|c|c|c|c|c|c|c|c|c|}
\hline & \multirow[t]{2}{*}{ Complete } & \multicolumn{3}{|c|}{ Anterior part incomplete, $\%$} & \multicolumn{4}{|c|}{ Posterior part incomplete, $\%$} \\
\hline & & $\begin{array}{c}\text { Zero or } \\
\text { hypoplastic } \\
\text { Acom }\end{array}$ & $\begin{array}{l}\text { ACA from } \\
\text { ipsilateral } \\
\text { ICA }\end{array}$ & $\begin{array}{c}\text { ACA from } \\
\text { contralateral } \\
\text { ICA }\end{array}$ & $\begin{array}{c}\text { Zero or } \\
\text { hypoplastic } \\
\text { Pcom on one } \\
\text { side }\end{array}$ & $\begin{array}{c}\text { Zero or } \\
\text { hypoplastic } \\
\text { Pcom on both } \\
\text { sides }\end{array}$ & $\begin{array}{l}\text { Dominance } \\
\text { of Pcom } \\
\text { on one side }\end{array}$ & $\begin{array}{c}\text { Dominance } \\
\text { of Pcom on } \\
\text { both sides }\end{array}$ \\
\hline NA & 8.3 & 9.4 & 100 & 0 & 31.3 & 18.8 & 37.5 & 9.4 \\
\hline ME & 22.2 & 21.8 & 57.1 & 42.9 & 26.5 & 21.8 & 18.7 & 6.3 \\
\hline
\end{tabular}

Table 2. Morphometry of the components of the posterior part of circle of Willis in the Caucasian (NA) and Arabic (ME) cohorts (mean $\pm \mathrm{SD}, \mathrm{mm}$ ).

\begin{tabular}{|c|c|c|c|c|c|c|c|c|c|}
\hline & \multicolumn{2}{|c|}{ P1 } & \multicolumn{2}{|c|}{ P2 } & \multicolumn{2}{|c|}{ Pcom } & \multicolumn{2}{|c|}{ ICA } & \multirow[t]{2}{*}{ BA } \\
\hline & right & left & right & left & right & left & right & left & \\
\hline NA & $\begin{array}{c}2.27 * * \\
\pm 0.6254\end{array}$ & $\begin{array}{c}2.34^{* *} \\
\pm 0.5143\end{array}$ & $\begin{array}{c}2.61 * \\
\pm 0.4768\end{array}$ & $\begin{array}{c}2.49 * \\
\pm 0.3524\end{array}$ & $\begin{array}{c}1.54^{\star *} \\
\pm 0.6811\end{array}$ & $\begin{array}{c}1.58^{*} \\
\pm 0.7114\end{array}$ & $\begin{array}{c}4.54^{\star *} \\
\pm 0.6084\end{array}$ & $\begin{array}{c}4.50^{\star * *} \\
\pm 0.5721\end{array}$ & $\begin{array}{c}4.08^{\star *} \\
\pm 0.8121\end{array}$ \\
\hline ME & $\begin{array}{c}1.89^{*} \\
\pm 0.7107\end{array}$ & $\begin{array}{c}2.14^{* *} \\
\pm 0.4069\end{array}$ & $\begin{array}{c}1.99^{*} \\
\pm 0.2228\end{array}$ & $\begin{array}{c}1.95^{\mathrm{NS}} \\
\pm 0.2564\end{array}$ & $\begin{array}{c}1.49^{\mathrm{NS}} \\
\pm 0.5666\end{array}$ & $\begin{array}{c}1.36^{\star} \\
\pm 0.3299\end{array}$ & $\begin{array}{c}4.36^{\star *} \\
\pm 0.5472\end{array}$ & $\begin{array}{c}4.43^{* *} \\
\pm 0.3224\end{array}$ & $\begin{array}{c}3.86^{* *} \\
\pm 0.4151\end{array}$ \\
\hline
\end{tabular}

Significance levels: ${ }^{* * *} \mathrm{p}<0.01 ;{ }^{* *} \mathrm{p}<0.01{ }^{*} \mathrm{p}<0.5 ;^{\mathrm{NS}}-$ statistically insignificant. 
The morphologic analysis of the contributing to the posterior cerebral artery vessels shows that the basilar artery is the main source of the perfusion in $67.5 \%$ of Caucasian study group and $72.45 \%$ of the Arabic one (Table 3). The internal carotid artery takes over the posterior circulation in $21.1 \%$ of the Caucasian cohort, and in $15.7 \%$ of the Arabic cohort. The co-contribution of both internal carotid and basilar arteries in feeding of the posterior cerebral artery was found in $11.25 \%$ of the Caucasian specimens and in $17.05 \%$ of the Arabic ones (Figure 7).

\section{Discussion}

The anatomical variability of the patterns of the circle of Willis in different ethnic and racial groups is frequently disputed by authors. Although some authors have found no evidence of differences in various populations [4], others describe certain prevalence of one vascular pattern over the other in studied cohorts [3] [5] [7]. Comparison of the data obtained by authors from the different populations shows that all segments of the cerebral arterial ring were well developed in $37.2 \%$ of patients in Kenya, $28.4 \%$ of individuals in Iran, and only in $14.5 \%$ of the studies group in France (Table 4). The anterior communicating artery was better developed in the results obtained from Iran, Kenya, India and France, while the posterior communicating artery was better presented in the studied group from Morocco.

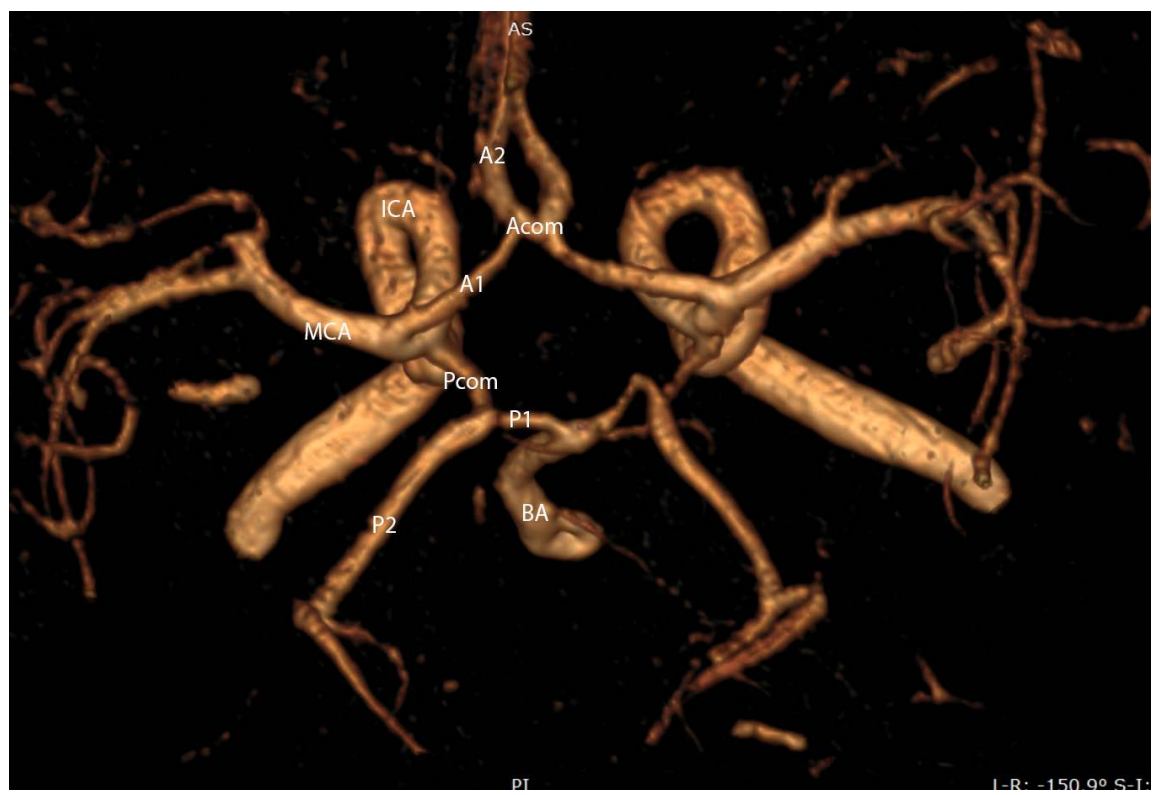

Figure 7. Cerebral MRA, 3D volume rendering (superior view) showing the co-contribution of both the internal carotid (ICA) and basilar (BA) arteries in feeding of the posterior cerebral artery (PCA) (partial fetal circulation). Other abbreviations: Pcom: posterior communicating artery, P1: precommunicating segment of PCA, P2: postcommunicating segment of PCA, A1: precommunicating segment of anterior cerebral artery, A2: postcommunicating segment of the anterior cerebral artery, MCA: medial cerebral artery. 
Table 3. Contribution of the internal carotid (ICA) and basilar (BA) arteries in irrigation of the posterior cerebral territories in the Caucasian (NA) and Arabic (ME) cohorts.

\begin{tabular}{|c|c|c|c|c|c|c|}
\hline & $\begin{array}{l}\text { BA dominance } \\
\quad(C D>1.2)\end{array}$ & $\begin{array}{c}\mathrm{Ba} \text { and ICA } \\
\text { co-contribution } \\
(\mathrm{CD} 81-1.21)\end{array}$ & $\begin{array}{l}\text { ICA dominance } \\
\quad(C D<0.8)\end{array}$ & $\begin{array}{l}\text { BA dominance } \\
\quad(\mathrm{CD}>1.2)\end{array}$ & $\begin{array}{c}\mathrm{Ba} \text { and ICA } \\
\text { co-contribution } \\
(\mathrm{CD} 81-1.21)\end{array}$ & $\begin{array}{l}\text { ICA dominance } \\
\quad(C D<0.8)\end{array}$ \\
\hline & & Right side & & & Left side & \\
\hline $\begin{array}{c}\text { NA } \\
\text { (right side } n=28 \\
\text { left side } n=24)\end{array}$ & $64.2 \%(18)$ & $14.2 \%(4)$ & $21.4 \%(6)$ & $70.8 \%(17)$ & $8.3 \%(2)$ & $20.8 \%(5)$ \\
\hline $\begin{array}{c}\text { ME } \\
\text { (right side } n=30 \\
\text { left side } n=29 \text { ) }\end{array}$ & $77.7 \%(21)$ & $14.8 \%(4)$ & $18.5 \%(5)$ & $61.2 \%$ (19) & $19.3 \%(6)$ & $12.9 \%(4)$ \\
\hline
\end{tabular}

Table 4. Comparison of variations of the vessels of the circle of Willis in different cohorts worldwide.

\begin{tabular}{|c|c|c|c|c|c|c|c|c|c|c|}
\hline Cohort & Complete & $\begin{array}{l}\text { Norm } \\
\text { Acom }\end{array}$ & $\begin{array}{l}\text { Zero or } \\
<1 \mathrm{~mm} \\
\text { Acom }\end{array}$ & $\begin{array}{l}\text { Double } \\
\text { Acom }\end{array}$ & Hypo A1 & $\begin{array}{c}\text { Normal } \\
\text { Pcom }\end{array}$ & $\begin{array}{c}\text { Zero or } \\
<1 \mathrm{~mm} \\
\text { Pcom }\end{array}$ & $\begin{array}{c}\text { P1 < Pcom } \\
\text { (unilateral } \\
\text { partial fetal) }\end{array}$ & $\begin{array}{c}\text { P1 }<\text { Pcom } \\
\text { (bilateral } \\
\text { partial fetal) }\end{array}$ & $\begin{array}{c}\text { No P1 } \\
\text { (complete } \\
\text { fetal) }\end{array}$ \\
\hline India [9] & $22.14 \%$ & $52 \%$ & $5 \%$ & $5 \%$ & $9.28 \%$ & $12.8 \%$ & $19.3 \%$ & $15.6 \%$ & $4.3 \%$ & $5.7 \%$ \\
\hline Kenya [3] & $37.20 \%$ & $78.7 \%$ & $4.30 \%$ & $0 \%$ & $11.7 \%$ & $27.7 \%$ & $41.5 \%$ & $13.8 \%$ & $7.40 \%$ & $5.30 \%$ \\
\hline Taiwan [6] & $21.30 \%$ & $64.1 \%$ & $11.44 \%$ & $1.18 \%$ & $9.86 \%$ & $14.40 \%$ & $42.80 \%$ & $20.71 \%$ & $5.92 \%$ & $4.14 \%$ \\
\hline Iran [4] & $28.4 \%$ & - & $0 \%$ & $0 \%$ & $0 \%$ & $30 \%$ & $19.6 \%$ & $7 \%$ & $0 \%$ & $0 \%$ \\
\hline Morocco [7] & $18 \%$ & - & $11 \%$ & $0 \%$ & $2 \%$ & $40 \%$ & $25 \%$ & $14 \%$ & $1 \%$ & $0 \%$ \\
\hline France [8] & $14.5 \%$ & - & $4.5 \%$ & $0 \%$ & $1.5 \%$ & $30.5 \%$ & $14.5 \%$ & $7.5 \%$ & $4.5 \%$ & $0 \%$ \\
\hline
\end{tabular}

To compare the vascular pattern of the circle of Willis in ethnically and racially different groups, we have studied this subject in two geographically separated cohorts: North American Caucasian descent, and Middle East Arab descent. Based on our results, the pattern of the blood perfusion of the anterior part of the brain is more permanent in the Caucasian cohort, where the anterior cerebral arteries branch off from the ipsilateral ICA and the anterior communicating artery is ineffective only in $9.4 \%$ of cases (Table 1). The Arabs study group expressed wide range of variability of the $\mathrm{A} 1$ and anterior communicating arteries, with frequent hypoplasia of these vessels and branching of both A2 segments from the unilateral ICA. Such variation of blood distribution puts pressure on the only feeding internal carotid artery and restrains the plasticity of the anterior circulation (Figure 2).

In their genetic research on variability of the anterior part of the circle of Willis in gerbils, Li $\mathrm{Z}$ et al. have identified 4 proteins related to the development of the anterior communicating artery by methods of qPCR, SSH, and Western blotting [11]. Authors have discovered that the expression level of CST3 was higher in brains with a well-developed anterior communicative artery, while the expression level of PFN2 was higher in the brains with incomplete anterior part of the circle of Willis. Additionally, the expression of GPx4 and GNAS differed 
significantly in the study groups. Their findings show the strong association of these genes with the variability of the anterior part of the cerebral arterial circle [11]. We suggest that the wide range of patterns in the anterior part of the circle of Willis in the Arabic study group may be associated with increased expression of PFN2 in this population.

Analysis of the posterior part of the circle of Willis shows a wide range of patterns in terms of the development of P1 and Pcom segments, and signs of fetal circulation (Figures 3-7). The presence of the efficient posterior communicating artery is a vital factor for patients with the cerebral vascular accidents, as this vessel links the anterior and posterior cerebral circulations providing a powerful source of plasticity in cerebral hemodynamics. According to the clinical trial of Raamt et al., the redistribution of blood flow between the anterior and posterior circulations is crucial in the development of the leptomeningeal anastomoses in the patients recovering after stroke, and the chances are limited for the individuals with fetal circulation, then this connection is interrupted [13]. The clinical importance of the fetal circulation was highlighted in the work of Rosham KA et al. [14]. According to the authors, even patients with a partial fetal circulation have a strong chance of having a recurrent ischemic stroke, not to mention the patients with complete fetal type of cerebral circulation. The differentiation between the partial and complete types of the fetal circulation used by the authors to explain the basic concept of blood distribution does not provide the proper metric analysis and may lead to confusions in interpretation of the data by followers. The P1/Pcom coefficient of dominance proposed in the current research is designed to unify the differentiation of the types of the fetal circulation and may be considered as an addition to the previously used classification.

According to our results, the complete fetal circulation, which is characterized by the dominance of the internal carotid artery in the perfusion of the posterior territories, occurs in the Caucasian cohort almost twice as often as that in the Arabic one (Table 3). The partial fetal circulation with co-contribution of the main feeding vessels prevails in the study group from the Middle East (Figure 5). Such difference in variations of the posterior part of the cerebral arterial circle may determine the peculiarities of clinical presentation and evolving of the cerebrovascular disease in studied cohorts and is a subject for the future studies.

\section{Conclusion}

The present study reveals that the configuration of the cerebral arterial circle expresses some difference in the North American Caucasian versus the Middle Eastern Arabic cohorts. The anterior communicating and A1 segment of the anterior cerebral artery are disposed to alterations in the study group from the Middle East, jeopardizing the blood perfusion to the anterior territories of the brain. On the other hand, the development of the posterior communicating artery and P1 segment of the posterior cerebral artery vary significantly in the study group from North America, putting the posterior circulation at risk. 


\section{Limitations}

There are certain limitations of this study which may have an influence on the outcome.

1) Although the outcomes show a certain tendency in distribution of variants, the small number of cases makes the study less reliable. The continuation of this study with a larger sample size is advisable.

2) The MRA resolution does not allow to recognize vessels with the diameter less than $1 \mathrm{~mm}$. To overcome this limitation, all the cadaveric vessels less than 1 $\mathrm{mm}$ width were considered as hypoplastic or absent.

3) A $0.3-0.5 \mathrm{~mm}$ difference in the measurement of the diameters of the vessels was assumed, as the outer diameter was taken on the cadaveric specimens and the inner diameter on the MR images. To cover this difference, the ratio of diameters in both groups was calculated prior to comparison.

\section{Authors Contribution}

MK: Conceived and designed the analysis, collected the cadaveric data, performed the analysis, wrote the paper.

AH: Contributed MRI specimens and DICOM analysis tools, performed the analysis.

AP: Collected the cadaveric data, performed literature review, participated in writing of the paper.

MA: Collected the cadaveric data, performed literature review, participated in writing of the paper.

\section{Conflicts of Interest}

The authors declare no conflicts of interest regarding the publication of this paper.

\section{References}

[1] CDC (2017) National Center of Health Statistics. https://www.cdc.gov/nchs/fastats/leading-causes-of-death.htm

[2] Hamming, A.M., Walderveen, M.A., Mulder, I.A., et al. (2019) Circle of Willis Variations in Migraine Patients with Ischemic Stroke. Brain and Behavior, 9, e01223. https://doi.org/10.1002/brb3.1223

[3] Machasio, R.M., Nyabanda, R. and Mutala, T.M. (2019) Proportion of Variant Anatomy of the Circle of Willis and Association with Vascular Anomalies on Cerebral CT Angiography. Radiology Research and Practice, 2019, Article ID 6380801. https://doi.org/10.1155/2019/6380801

[4] Eftekhar, B., Dadmehr, M., Ansari, S., et al. (2006) Are the Distributions of Variations of Circle of Willis Different in Different Populations? Results of an Anatomical Study and Review of Literature. BMC Neurology, 6, 22. https://doi.org/10.1186/1471-2377-6-22

[5] Silva, D.R., Silva, R.W., Gunasekera, W.S. and Jayesekera, R.W. (2009) Prevalence of Typical Circle of Willis and the Variations in the Anterior Communicating Artery: 
A Study of a Sri Lankan Population. Annals of Indian Academy of Neurology, 12, 157-161. https://doi.org/10.4103/0972-2327.56314

[6] Chen, H.W., Yen, P.S., Lee, C.C., Chen, C.C., Chang, P.Y., et al. (2004) Magnetic Resonance Angiographic Evaluation of Circle of Willis in General Population: A Morphologic Study in 507 Cases. Chinese Journal of Radiology, 29, 223-229.

[7] Khamlichi, A., Azouzi, M., Bellakhdar, F., Ouhcein, A. and Lahlaidi, A. (1985) [Anatomic Configuration of the Circle of Willis in the Adult Studied by Injection Technics. Apropos of 100 Brains]. Neurochirurgie, 31, 287-293.

[8] Lazorthes, G., Gouaze, A., Santini, J.J. and Salamon, G. (1979) The Arterial Circle of the Brain (Circulus Arteriosus Cerebri). Anatomia Clinica, 1, 241-257. https://doi.org/10.1007/BF01654581

[9] Saikia, B., Handique, A., Phukan, P., Lynser, D. and Sarma, A. (2014) Circle of Willis: Variant Forms and Their Embryology Using Gross Dissection and Magnetic Resonance Angiography. International Journal of Anatomy and Research, 2, 344-353.

[10] Kammen, S.M., Moomaw, C.J., Schaaf, I.C., Brown Jr., R.D., Woo, D., Broderick, J.P., et al. (2018) Heritability of Circle of Willis Variations in Families with Intracranial Aneurysms. PLoS ONE, 13, e0191974.

https://doi.org/10.1371/journal.pone.0191974

[11] Li, Z., Huo, X., Zhang, S., Lu, J., Li, C., Guo, M., et al. (2015) Selection of Genes Associated with Variations in the Circle of Willis in Gerbils Using Suppression Subtractive Hybridization. PLOS ONE, 10, e0127355.

https://doi.org/10.1371/journal.pone.0127355

[12] Hoksbergen, A., Majoie, C., Hulsmans, F.J. and Legemate, D. (2003) Assessment of the Collateral Function of the Circle of Willis: Three-Dimensional Time-of-Flight MR Angiography Compared with Transcranial Color-Coded Duplex Sonography. American Journal of Neuroradiology, 24, 456-462.

[13] Raamt, A.F., Willem, M., Laar, P. and Graaf, Y. (2006) The Fetal Variant of the Circle of Willis and Its Influence on the Cerebral Collateral Circulation. Cerebrovascular Diseases, 22, 217-224. https://doi.org/10.1159/000094007

[14] Roshan, K.A., Tingting, Z. and Yicheng, Z. (2014) The Study of Fetal-Type Posterior Cerebral Circulation on Multislice CT Angiography and Its Influence on Cerebral Ischemic Strokes. Clinical Imaging, 38, 221-225.

https://doi.org/10.1016/j.clinimag.2014.01.007 